\title{
Discussion on Current Situation of College Information Construction and Its Measures
}

\author{
Jiaqi Mei \\ Jiujiang University \\ Jiujiang, Jiangxi, China \\ audiomjq@163.com \\ E-mail: 71290314@qq.com
}

\begin{abstract}
College information construction is a requisite for higher education modernization, and for enhancing teaching management level under the background of global informatization. Integrating information technology into the entire process of education and teaching is playing a role of innovative talents cultivation and education reform promotion in terms of continuous education level promotion and innovation in new era. At the same time, we need to know that college information construction is not only a comprehensive information technology project, but also a long lasting work with constant development and improvement. Only by establishing a new information service concept, innovating and setting up brand new information service mechanism and means, can the colleges adapt to and face the potential future development, thus to promote college information construction.
\end{abstract}

\section{Keywords—network; information service; digital campus}

\section{INTRODUCTION}

College information construction has far-reaching influence on the development and reform of various colleges, and has changed the education thought, education concepts, education mode, teaching contents and teaching methods and education evaluation system of various colleges profoundly. After human society has entered into the information-based society, the knowledge update cycle is shortened dramatically, and only the ability to control knowledge is mastered, can one be able to survive the modern society. Meanwhile, college information construction has promoted the closed higher education moving towards an open one gradually, and the construction of digital campus, as well as the digitization and multimedia of the digital contents have expanded the space and time of education and the objects of education greatly, making the mass education and life-long education possible. The application of modern information technology and the introduction of new educational thought will render more flexible teaching organization forms and teaching programs, as well as more targeted and designable teaching etc.. With the deepening of college information construction, colleges will certainly appreciate the significant promotion brought by information construction to higher education profoundly.

Informatization has been proposed to the level of national strategy at the party's fifth plenary session for the first time, and been taken as an important force for promotion of economic and social reform. It has become a strategic initiative covering China's overall modernization construction, and is the urgent need and inevitable choice for implementing the scientific concept of development, building a moderately prosperous society in all aspects, establishing the harmonious socialist society and building a harmonious socialist society as well as building an innovation-oriented nation. Informatization has been proposed to be called together with industrialization, urbanization, marketization and internationalization the five strategic tasks to strive to socialism with Chinese characteristics at the CPC's 17th National Congress, and the strategic position of informatization has been enhanced to an unprecedented height.

The "Report on Suggestion for the Projects within Education Informatization Fields of Action Plan for Invigorating Education 2008--2012" has been completed by the experts organized by the Ministry of Education in November 2007 with the objectives to establish and improve the educational network as well as educational resources construction and service system covering various educational institutions and schools at all levels nationwide, to build the national educational e-government platform, support and guarantee system of educational informatization application, to improve the public service system of educational informatization, to enhance teachers' application level of information and technology at large, to promote the in-depth application of information technology in education and teaching, to comprehensively enhance the quality of teaching and the educational supervision ability, and to promote the rapid development of China's educational modernization.

According to statistics, the applicants for College Entrance Examination have exceeded 10 million for 3 consecutive years of 2007--2009, while the average national college enrollment rate is around $60 \%$, from which we can see the increasing demands of the entire society for higher education. Such kind of growth is an opportunity for higher education, yet it is a challenge at the same time. To meet the opportunities and challenges, college information construction needs to develop into a new level as well.

Generally, China's college information construction has made a great historic breakthrough since the reform and 
opening up, yet it faces a series of outstanding issues at the same time.

\section{CurRent Situation AND PROBlems of College INFORMATION CONSTRUCTION}

\section{A. Rapid Development of Infrastructure Construction}

Colleges have all built a campus network with a coverage reaching $90 \%$ of student dormitory and buildings for teaching, research and administration, and the proportion of wireless network covering the public area reaches $80 \%$. CERNET has connected the colleges, educational institutions and research institutes of more than 200 cities, and networking unit has reached more than 2000 with users of more than 20 million, being the largest national academic Internet in the world. Meanwhile, China Grid has made significant progress. Through the grid supporting platform (CGSP) researched and developed independently, China Grid has integrated such information resources as calculation, storage, data and software covering 20 key universities within 13 provinces and cities in China. Moreover, the resources with computing capacity of 16 trillion times and storage capacity of 180TB have been established, and a range of typical grid applications have been developed with the overall size and core technology reaching the international advanced level.

\section{B. Prototype of Digital Resources System Basically Formed}

"China Academic Library \& Information System" has more than 500 libraries as its members, the data of union catalog database amounts to 1.8 million, and the collection has reached 7 million; "China Academic Humanities and Social Sciences Library" has a collection of nearly 2,800 kinds of foreign language periodicals and 370,000 kinds of foreign language books, and it provides document delivery services to the colleges nationwide with nearly 4000 registered users and over one hundred member libraries; "University Digital Museum" construction project has gathered basic resources of more than 100,000 pieces of high-quality teaching specimens and characteristic collections from 30 institutions of higher education covering geosciences, humanities, bioscience as well as science and technology.

A majority of colleges have established a teaching resource library, including multimedia material library, multimedia courseware library, electronic teaching library, teaching case library, test library etc; $50 \%$ of the colleges has established a unified teaching resources management platform in the whole school with an average digital teaching resources up to $850 \mathrm{~GB}$, and $90 \%$ of colleges have established electronic book resources with an average electronic book resources of 300,000 and above.

Great Progress Made in Informationized Education and Application

Information technology has been generally adopted by colleges to improve teaching methods of $65 \%$ of curriculums applying multimedia teaching, and $67 \%$ of colleges have built a network (assistant) teaching platform, the curriculums adopting network-assisted teaching has reached $21 \%$, discipline information construction of higher education has been further improved, $18 \%$ of colleges have established a collaboration platform for scientific research projects, $21 \%$ of colleges have established a sharing platform for scientific research knowledge, average discipline resource base constructed uniformly per school is 5.7 , and the total amount of digital resource of various disciplines reaches 1.957TB per school.

\section{Booming Electronic School}

The electronic school level of colleges has attain a continuous enhancement with most of them have established their homepage, $59 \%$ of colleges have build schools e-mail system, $36 \%$ of colleges have built campus bulletin system, $56 \%$ of them have built card system, $85 \%$ of them have established an electronic school affairs system to provide service to such aspects as teaching, scientific research, management and life, among which $30 \%$ of schools have realized informatization in terms of such main school affairs as teaching management, scientific research management, personnel management and financial management. Moreover, another $8.9 \%$ of the schools have built an integrated and unified management information platform at school level, with early warning by monitoring and decision support system having been applied primarily, which has greatly enhanced school's management level and operating efficiency.

\section{Security Mechanism of Information Construction to Gradually Get Attention}

$39.6 \%$ of schools have the plan to list informatization separately, $35.5 \%$ of schools will disperse informatization planning policy into the overall planning strategy, $46 \%$ of schools will separate the budget for school informatization as an overall informatization budget for the whole school, 33\% of schools has distributed their informatization budget in the department budget, and the total investment in information construction has reached 8.27 million annually, annual operation and maintenance costs is 930,000 yuan per school, training and research funding is 250,000 yuan per school, $64 \%$ of schools conduct information technical training for their personnel at a fixed period, people who receive the information training organized by schools up to 276 annually, $64 \%$ of schools have requirements of information technology for personnel to be employed, and each of the team of information construction, management and service contains about 30 people.

\section{E. Expanding Educational Scale of Information-based Talents}

In 2007, the students at school who are specialized in information of regular higher education in China have exceeded 3.168 million. As of March 2006, a total of 36 normal software colleges have been established, cultivation and training bases for talents in short supply of national computer technology and software application skills have reached 180 with 10 training base of national integrated circuit. Network higher network include 180 specialties 
within 10 disciplines, with an accumulated 6.67 million students of registered academic education, and annual enrollment has reached 1.85 million.

\section{F. Standardization Progress with Promotion of Health and Regulated Educational Information Development}

"Subcommittee of Educational Technology of National Information Technology Standardization Committee" (hereinafter referred to as "CELTSC") was formally established in 2001, and has released a series of criteria and specification relating to college information work, including "Education Management Information Standards", with the standardization evaluation, certification and demonstration having been launched. Colleges' standardized consciousness has been strengthened gradually, with $52 \%$ of schools using national or industrial data standards in formulating information encoding standards, $46 \%$ of schools having established a school uniform information coding standard, $81 \%$ of schools having developed and implemented specification of operation, maintenance, services and management for informatization.

However, behind the accomplishments, many problems have begun to stand out. According to Director of Information Department of the Ministry of Education, current problems exist in college informatization are as below:

1)Uneven Informatization Development: According to the result of undergraduate college informatization assessment conducted recently in Guangdong Province: As for information construction, $24 \%$ of the colleges possess strong institution, perfected infrastructural facilities, wellbuilt digital campus and excellent application effects; the colleges that have specific institution, basically perfected infrastructural facilities, partly digital campus construction and application account for 54\%; while the colleges with imperfect institutions, infrastructural facilities unable to meet requirements and little digital campus construction and application account for 19\%; and there are still $3 \%$ of schools have neither the relevant agencies of information construction, nor the campus network. Guangdong Province is a province with quite higher overall level of college information construction level, and the situation in other provinces is conceivable.

2)Serious Islanding Phenomenon: College informatization is facing two islanding problems in terms of data and application. The decentralized management of data makes it difficult to share as it may be inaccurate, irregular and inconsistent; as for application, there exist such manmade islanding problems as independent construction of various departments, disunity of technology, disunity of users and connection among applications with difficulty. The reason for that is colleges are short of top-level design, technical specifications and information standards when carrying out information construction in terms of technology. And administrative reasons, namely lack of coordination and organization, shall not be ignored.
3)Insufficient Knowledge about Strategic Position of Informatization, Lack of Coordination and Overall Planning: Some colleges do not pay attention to informatization, as they tend to believe that informatization is to make modern colleges even better but not an inevitable choice; deviation exist in quite a few colleges' understanding of informatization, or lack of in-depth understanding, with serious problem of ignoring services. Capital investment is short of long-term investment guarantee mechanism. In the implementation of enterprise ERP, the ratio between hardware, software and service funding is usually 2: 3:5, while in the process of college information construction, colleges tend to pay attention to construction but ignore application, and the problems of ignoring application promotion has appeared clearly, which has resulted in the poor performance in information construction.

4)Management Mechanisms Still Need to be Improved: Many schools have not yet established an effective mechanism for information construction, management and operation, specifically as: unsound organization, weak coordination; multiple and decentralized management or even no management.

\section{DISCUSSION ON INFORMATION CONSTRUCTION MEASURES}

\section{A. Establish a Sustainable System for Educational Informatization Organization and Security}

State education administrative departments at all levels shall establish or improve special educational informatization organization and management institution, implement institutional facilities, staffing and special funds, match corresponding management system, thus to form a unified top-down system for educational informatization organization and security; colleges shall establish the "informatization office" that is in charge of colleges" informatization organization, management and coordination comprehensively, and gradually set the executive vice president as CIO; and establish the construction mechanisms and operating mechanisms that meet educational development law to ensure sustainable development of educational informatization.

\section{B. Establish a Diversified Educational Informatization Funding Mechanism}

Encourage multi-investment to form a diversified investment structure, and establish the sustainable operation and development funding resources mechanisms for educational informatization on the basis of overall planning of educational informatization; list the educational information construction into educational funding budget, implement all cycle budget to form a stable financial investment channels, establish an ongoing national investment mechanism with certain amount, so that educational informatization investment will account for a certain percentage of total education investment, give full play to enthusiasm of local governments to ensure stable local financial investment, meanwhile regional distribution shall be taken into full account. 


\section{Vigorously Promote the Integration of Information Technology and Education Development}

Carry out various key applications of education and teaching in-depth, and vigorously promote the integration of information technology and education; actively promote the integration of multimedia teaching; actively promote multimedia teaching, blended learning and online learning to realize organic combination and deepening application of information technology and education; further deepen the role of information technology in promoting educational reform and development through effective subject research, thus to promote improvement of education quality.

\section{Establish Sharing Mechanism of Educational \\ Information Resources}

Strengthen the overall planning, coordinating construction and management of educational information resources; establish and improve the development of educational information resources with good quality; establish sharing mechanism of educational information resources; improve intellectual property protection system; promote the construction of a educational information resource service system at national level; promote collection and standard formulating of educational information resources to realize the in-depth development, timely treatment, safe storage, fast-flowing and effective use of high-quality educational information resources.

\section{CONCLUSION}

With the further development of college information construction, the traditional information service is increasingly subject to the impact of modern technology. The characteristics of information services, such as "network, two-way interaction, man-machine friendly, multi-direction discussion and all day long", have become more prominent. Only by adhering to a concept of full range, in-depth, multiangle and mutual contact, can the information service institutions make a good job of information services. And in the era of informatization, information services must be socially oriented, and shall expand the user-oriented, diversified and in-depth services, in order to better serve and promote the college information construction.

\section{REFERENCES}

[1] ]Yang Fuyun. Problems Exist in College Information Service and Solutions [J].Journal of Fujian Agriculture and Forestry University (Version of Philosophy and Social Science), 2004,7 (2) : 94-96.

[2] Yang Lihui. Current Situation of College Information Service and Realization of Marketing Concept [J].The Commercial Economy, 2005,9:78-79.

[3] Lin Chen, Chen Xiaoning, Liu Bingzheng. Discussion on College Information Service Management and Practice [J]. Higher Education in Chemical Engineering, 2009,3: 92-96 